\title{
Neurosurgery for schizophrenia: an update on pathophysiology and a novel therapeutic target
}

\author{
Charles B. Mikell, MD, ${ }^{1}$ Saurabh Sinha, BS, ${ }^{2}$ and Sameer A. Sheth, MD, PhD ${ }^{1}$ \\ 'Department of Neurological Surgery, Columbia University Medical Center, New York, New York; and 2Division of Neurosurgery, \\ Rutgers Robert Wood Johnson Medical School, New Brunswick, New Jersey
}

\begin{abstract}
The main objectives of this review were to provide an update on the progress made in understanding specific circuit abnormalities leading to psychotic symptoms in schizophrenia and to propose rational targets for therapeutic deep brain stimulation (DBS). Refractory schizophrenia remains a major unsolved clinical problem, with $10 \%-30 \%$ of patients not responding to standard treatment options. Progress made over the last decade was analyzed through reviewing structural and functional neuroimaging studies in humans, along with studies of animal models of schizophrenia. The authors reviewed theories implicating dysfunction in dopaminergic and glutamatergic signaling in the pathophysiology of the disorder, paying particular attention to neurosurgically relevant nodes in the circuit. In this context, the authors focused on an important pathological circuit involving the associative striatum, anterior hippocampus, and ventral striatum, and discuss the possibility of targeting these nodes for therapeutic neuromodulation with DBS. Finally, the authors examined ethical considerations in the treatment of these vulnerable patients. The functional anatomy of neural circuits relevant to schizophrenia remains of great interest to neurosurgeons and psychiatrists and lends itself to the development of specific targets for neuromodulation. Ongoing progress in the understanding of these structures will be critical to the development of potential neurosurgical treatments of schizophrenia.
\end{abstract}

http://thejns.org/doi/abs/10.3171/2015.4.JNS15120

KEY WORDS deep brain stimulation; fMRI; functional neurosurgery; neuroimaging; schizophrenia

$\mathrm{S}$ CHIZOPHRENIA is a heterogeneous disorder characterized by varying degrees of positive psychotic symptoms, negative symptoms, and cognitive impairment. ${ }^{48}$ With a prevalence of $1.1 \%$ in the US, ${ }^{93}$ schizophrenia is a major health burden, increasing the risk for numerous adverse outcomes, including the inability to maintain a stable residence, maintain a job, or find a spouse. ${ }^{39}$ Moreover, $10 \%-30 \%$ of patients with schizophrenia have little or no response to antipsychotic treatment..$^{68}$ Limited treatment options are available after first-line therapies have failed. Potential therapies for refractory schizophrenia include clozapine, electroconvulsive therapy, and repetitive transcranial magnetic stimulation (rTMS), but many patients continue to have symptoms despite maximal medical management. ${ }^{57}$ New treatment strategies are therefore needed.

Although deep brain stimulation (DBS) is chiefly used in the treatment of movement disorders, its use in behav- ioral disorders is expanding. In 2009, the FDA awarded DBS a humanitarian device exemption (HDE) for obsessive-compulsive disorder (OCD). Given preliminary evidence of efficacy in OCD, ${ }^{29,33,69,91}$ the use of DBS to treat other psychiatric disorders, including depression, Tourette syndrome, and even autism, is expanding. ${ }^{111}$ Currently, interest in treating schizophrenia using DBS is growing, and a clinical trial is now open in Canada for the treatment of refractory schizophrenia. ${ }^{16}$ Moreover, the growing use of DBS for behavioral indications has been accompanied by an expansion in understanding of the underlying pathophysiology of psychiatric disease. In the case of schizophrenia, there is increasing acceptance that the disorder is characterized by dysfunction in the hippocampus and striatum, suggesting possible targets for intervention. ${ }^{54}$ Given our increasing understanding of the neuroanatomy of schizophrenia, the time is ripe for the development of novel circuit-based therapies, including DBS.

ABBREVIATIONS AST = associative striatum; BOLD = blood oxygen level-dependent; $\mathrm{cSP}=$ cortical silent period; $\mathrm{DBS}=$ deep brain stimulation; $\mathrm{DLPFC}=$ dorsolateral prefrontal cortex; fMRI = functional MRI; GABA = gamma-aminobutyric acid; HDE = humanitarian device exemption; MDD = major depressive disorder; NMDA = N-methyl-Daspartate; $\mathrm{OCD}=$ obsessive-compulsive disorder; rCBF = regional cerebral blood flow; rTMS = repetitive TMS; SICI = short-interval intracortical inhibition; TMS = transcranial magnetic stimulation; VBM = voxel-based morphometry; VS = ventral striatum; VTA = ventral tegmental area.

SUBMITTED January 18, 2015. ACCEPTED April 23, 2015.

INCLUDE WHEN CITING Published online October 30, 2015; DOI: 10.3171/2015.4.JNS15120. 
We used PubMed to search for articles published from January 1980 to September 2014. The major search terms that we used included "schizophrenia," "imaging analysis," "fMRI," "animal model," "neuroanatomy" (along with the specific neuroanatomical regions noted in this review), and "deep brain stimulation." We reviewed the relevant articles from this search, including those that were referenced within each article. We included meta-analyses selected for robust statistical analysis, original research articles relevant to probing circuits involved in schizophrenia, and review articles.

In this paper we review progress made over the last several years in our understanding of the pathophysiology of schizophrenia. We begin by reviewing the current literature on the structural pathology of schizophrenia. Subsequently, we describe functional abnormalities that drive hyperactive and mistimed dopamine release. We then review transcranial magnetic stimulation (TMS), metabolic imaging, and functional MRI (fMRI) studies to identify specific anatomical nodes within circuits responsible for dopamine dysfunction in schizophrenia. We conclude by suggesting possible targets for surgery, including the anterior hippocampus, ventral capsule/ventral striatum (VS), and the associative striatum (AST). We propose concrete steps for the evaluation of each of these targets, as well as some considerations for trial design. Considerations in the development of putative closed-loop systems are discussed. Finally, we discuss the ethical implications of treating patients whose faculty for informed consent may be impaired by their disease.

\section{Structural Pathology in Schizophrenia}

In the late 1800s, Kraepelin and Bleuler hypothesized that the disease process underlying schizophrenia was ultimately governed by anatomical abnormalities of the brain. At that time, limited neuroimaging techniques and the lack of postmortem findings hindered progress in delineating the neuroanatomical characteristics of schizophrenia. Recent advances in MRI analysis, including voxel-based morphometry (VBM) to analyze structural abnormalities, and fMRI to analyze functional changes, have elucidated neuroanatomical and neurophysiological differences in patients with schizophrenia that can be linked to disease features. ${ }^{104}$

Because executive and cognitive deficits are a key symptom domain of schizophrenia, early anatomical studies explored differences in the frontal lobes that distinguished patients with schizophrenia from controls. ${ }^{4}$ Decreased integrity of the frontal neocortex, particularly in the prefrontal and orbitofrontal cortices, has been noted in several VBM studies and confirmed in a metaanalysis. ${ }^{38,44,104}$ Moreover, decreased frontal lobe volume, specifically of the prefrontal cortex, has been associated with decreased insight in patients with schizophrenia. ${ }^{7,23,63}$ However, it is unclear whether frontal lobe volume loss is a cause or a consequence of ongoing symptoms; some data suggest that volume loss is exacerbated with repeated episodes of psychosis. ${ }^{5,118}$ The reason for this progression has not been fully elucidated, but it has been proposed that prefrontal dysfunction is secondary to aberrant dopamine release and corresponding alterations in $\mathrm{D}_{1 / 2}$-receptor signaling. ${ }^{28}$ While prefrontal dysfunction may be a key cause of cognitive symptoms in schizophrenia, dysfunction elsewhere in the brain, especially the temporal lobes, may drive the neurotransmitter abnormalities that characterize the hallmark psychotic symptoms of schizophrenia.

Early functional neuroimaging studies sought to characterize the functional causes and/or consequences of the observed atrophy of the frontal and temporal lobes. Studies using blood oxygen level-dependent (BOLD) fMRI identified diminished frontal activation in patients compared with controls in response to the Stroop color interference test and the Wisconsin Card Sorting test, both established tests of attention and cognitive control. ${ }^{13,99}$ In a meta-analysis of task-related functional neuroimaging of patients with schizophrenia, Minzenberg and colleagues demonstrated that patients with schizophrenia had activation patterns similar to those in control patients during Stroop testing, but had reduced overall activation in several nodes, including bilateral dorsolateral prefrontal cortex (DLPFC) and posterior parietal and temporal cortices. ${ }^{83}$ However, there is some dispute about whether decreased frontal activation in patients with schizophrenia represents intrinsic circuit defects or a general problem with performing cognitive tasks. ${ }^{43}$ Nonetheless, the finding of decreased BOLD activation during cognitively demanding tasks appears robust.

Alterations in temporal lobe morphology, in comparisons with controls and also with disease progression, are among the earliest findings reported in neuroanatomical studies of schizophrenia. Early postmortem studies showed alterations in parahippocampal gyrus volume, increased lateral ventricle size, and left-sided lateralization of structural abnormalities relative to control subjects. ${ }^{104}$ The hippocampus, in particular, has been found to be smaller in patients with schizophrenia relative to that in controls; multiple meta-analyses have demonstrated hippocampal volume decreases averaging $5 \%$ in patients with schizophrenia. ${ }^{66,90} \mathrm{Kühn}$ and colleagues noted smaller CA2/3 and CA1 subfields specifically. ${ }^{61}$ Increased duration of illness is associated with even greater loss in bilateral hippocampal volume compared with first-episode psychosis. ${ }^{104}$ These data point to a key role for the hippocampus in schizophrenia.

These anatomical data support the hypothesis that schizophrenia is characterized by atrophy of the frontal and temporal lobes, including both neocortical and hippocampal structures, and may be progressive. Although many of the anatomical findings have now been reproduced in other studies, the understanding of the functional causes and consequences of these structural effects is only beginning to be understood.

\section{Findings From Transcranial Magnetic Stimulation: Evidence for Cortical Dysfunction in Schizophrenia}

In recent years, TMS has provided a noninvasive means of probing neurophysiology by applying a magnetic field to induce an electrical current in a specific cortical region. The cortical response to TMS paradigms can be tested, 
providing insight into network function and dysfunction. It has been used to study psychiatric diseases, such as OCD and major depressive disorder (MDD). ${ }^{11,35}$ Several studies have used TMS to analyze cortical function in schizophrenia as well.

TMS appears to have different effects on positive and negative symptoms, which may be present in distinct admixtures in individual patients with schizophrenia. As such, differential relationships have been observed when well-established TMS paradigms are applied to patients with positive symptoms versus those with negative symptoms. Paired-pulse TMS paradigms are one example of this, and they are used to measure intracortical facilitation and inhibition. ${ }^{77}$ Abnormalities in these parameters, believed to reflect gamma-aminobutyric acid (GABA)-ergic and glutamatergic activity, respectively, were originally described in Parkinson's disease,${ }^{96}$ but have since been shown to apply to a variety of neuropsychiatric diseases, such as OCD and MDD. In schizophrenia, positive symptoms are associated with a reduced short-interval intracortical inhibition (SICI), which itself suggests a baseline heightened cortical excitability. This deficit in inhibition is likely $\mathrm{GABA}_{\mathrm{A}}$-mediated and suggests that an imbalance in this receptor's signaling may play a role in the pathophysiology of positive symptoms. Negative symptoms of schizophrenia, however, do not tend to track with SICI, but rather do tend to track with a TMS measure called the cortical silent period (cSP), which is believed to reflect activity of $\mathrm{GABA}_{\mathrm{B}}$ receptors. ${ }^{77}$ In patients with negative symptoms of schizophrenia, an inverse association with cSP has been described. ${ }^{72,77}$ Neuroleptic-induced prolongation of cSP has also been described, suggesting a potential mechanism for predicting response to medication. ${ }^{77}$ Taken together, the insights from these TMS paradigms suggest a potential role for cortical GABA-ergic networks. As discussed below, this may eventually tie into largerscale dysfunction within corticostriatothalamocortical circuits to produce schizophrenia symptomatology.

TMS can also be used concurrently with electroencephalography to observe changes in oscillatory activity in various neural circuits. Frantseva and colleagues recently used this paradigm to study patients with schizophrenia. They found spreading excitation in response to TMS that lasted significantly longer than that in healthy controls, a phenomenon they termed "functional cortical conductivity." 25 Moreover, they correlated gamma band activation with positive symptoms and theta/delta activation with negative symptoms, suggesting a link between the nature of cortical conductivity and the heterogeneous symptomatology of schizophrenia. Identifying dysfunctional circuits in this manner is an important step toward therapy, as we will discuss later, and TMS has indeed been attempted as a therapeutic measure for schizophrenia.

Several case series demonstrate therapeutic utility for both rTMS and a TMS technique known as theta burst stimulation in schizophrenia. . $^{19,58,106,124}$ Some studies report safe, tolerable, and effective therapeutic intervention for positive symptoms ${ }^{19,58,106}$ and others for negative symptoms. ${ }^{124}$ Various regions have been targeted, including the cerebellar vermis and the left DLPFC, but long-term improvement in symptoms (i.e., past the stimulation period) is not typically reported. Moreover, any change in behavior and function is typically the result of 4-5 sessions of TMS per week, which can be demanding for the patient. Still, proof of safety and utility is conceptually promising for therapy targeted at neural networks, and DBS may provide a longer-lasting, modifiable therapeutic effect.

For all its insight into cortical function and dysfunction, however, TMS cannot directly provide information about subcortical structures, of which the striatum and dopaminergic midbrain serve as key pivots for both mechanistic and therapeutic considerations in schizophrenia. Neuroimaging studies have yielded insights into dysfunction within these structures.

\section{Functional Neuroimaging Studies in Schizophrenia: How Temporal Lobe Dysfunction May Lead to Too Much Dopamine in the Striatum}

The best-characterized functional neuroimaging findings in schizophrenia are aberrant striatal activation and frontal dysfunction. However, in contrast to the robust evidence for frontal and temporal anatomical abnormalities, evidence for anatomical pathology within the dopaminergic midbrain is limited. A consensus has emerged that dopamine dysregulation in schizophrenia is due to problems with either presynaptic regulation of dopamine axon terminals ${ }^{74}$ or polysynaptic circuits (including the hippocampus), or both, that normally ensure proper regulation of dopamine neuron firing. ${ }^{31}$ In this section, we begin by reviewing evidence for dopamine dysfunction in schizophrenia. Subsequently, we discuss results demonstrating that frontal dysfunction may arise from abnormal activity within the dopamine system. Finally, we summarize evidence suggesting that hippocampal dysfunction is the cause of the dopamine dysfunction in schizophrenia.

The "dopamine hypothesis" of schizophrenia arose from observations in the 1950s that agents such as reserpine and chlorpromazine, which affect the monoamine system, have therapeutic benefit in the treatment of psychotic symptoms. ${ }^{108}$ These empirical observations were substantiated with animal experiments, demonstrating that antipsychotic efficacy was correlated with the effect of these agents on the dopamine system. ${ }^{103}$ The hypothesis was thus formulated that delusions and hallucinations in schizophrenia were related to excessive dopamine release in the striatum by the substantia nigra, and its most medial part, the ventral tegmental area (VTA). ${ }^{109}$ However, the dopamine hypothesis was disputed ${ }^{3}$ until neurochemical studies using PET provided clear evidence for increased dopamine transmission in schizophrenia in the late 1990s (these studies are reviewed critically below). ${ }^{65}$ These neurochemical studies were accompanied by technical advances in fMRI that allowed imaging of the relatively small brain regions implicated in schizophrenia, including the substantia nigra, hippocampus, and subregions of the striatum, as well as advances in the mechanistic understanding of how these regions work together in normal and pathological circumstances.

Observations in animals that hippocampal activation leads to dopamine release from the VTA into the stria- 
tum $^{24}$ gave rise to the hypothesis that a novel stimulus or environment detected in the hippocampus uses dopamine as a downstream neurotransmitter to gate information transfer into long-term memory. ${ }^{71}$ Predictions of this model were confirmed using fMRI in healthy subjects. ${ }^{123}$ Soon afterward, aberrant midbrain activity in response to reward prediction errors (a strong stimulus for dopamine neuron firing, discussed further below) was demonstrated with fMRI in patients with schizophrenia. ${ }^{87}$ Theoretical models also advanced at this time to fill the explanatory gap between the finding of excessive dopamine release and the experience of psychosis.

Recently, a new model of the tonic and phasic firing states of midbrain dopaminergic signaling has provided a context within which to understand the aforementioned aberrant midbrain activity. Tonic-phasic signaling in the midbrain provides a system for stratifying the relative importance of sensory stimuli and, ultimately, at higher cortical levels, for imparting salience to those stimuli. In this framework, dopamine is released tonically by midbrain neurons in a pacemaker-like fashion to modulate frontostriatal networks and drive goal-directed behavior. ${ }^{53}$ Phasic changes from this baseline tonic dopaminergic signaling occur, with characteristic latencies and durations, in response to unexpected rewards or stimuli. ${ }^{102}$ These phasic changes represent a difference between the expected and actual reward from a stimulus, a quantity termed "prediction error." In fact, a robust, stereotyped system of patterns of activation or depression of dopaminergic neurons exists. Initially, there is brief activation that is standard for all types of stimuli. ${ }^{102}$ However, there is a second response component consisting of heterogeneous changes in dopaminergic neuronal firing dependent on the subjective value of the stimulus. ${ }^{102}$ This biphasic response was recently replicated in humans. ${ }^{82}$ These phasic changes reverberate within the circuit, and, at higher cortical levels (or, as Kapur puts it, the "mind level"), the net result of all of this signal integration is an assignment of relative salience to a stimulus. ${ }^{53}$ In psychosis, it is proposed that dysregulation of the tonic-phasic dopaminergic system results initially in misattributions of reward to stimuli that would otherwise be ignored, resulting in aberrant salience at those higher cortical levels, and finally manifesting clinically as the positive symptoms of schizophrenia, including delusions and hallucinations. ${ }^{53}$ Furthermore, functional neuroimaging studies have both confirmed elements of this hypothesis and extended its explanatory power by suggesting that the cause of the hyperdopamergic state is hyperactivity within the hippocampus.

Functional MRI studies of patients with schizophrenia have confirmed predictions of this "incentive salience" model by demonstrating aberrant activation within subcortical structures. In particular, altered ventral striatal response to neutral stimuli has been shown in patients with schizophrenia, and patients at high risk for psychotic episodes have demonstrated greater ventral striatal signals on fMRI in response to neutral stimuli. ${ }^{87,95,122}$ Incentive salience also exists within a broader cortical network as evidenced by task-specific BOLD activation in the dorsal anterior cingulate cortex, bilateral frontoinsular cortex, anterior insula, and inferior frontal gyrus. ${ }^{121}$ Interestingly, these regions are typically of lower volume in patients with schizophrenia. ${ }^{6}$ Yet, task-related fMRI studies in patients with schizophrenia show normal recruitment of cortical circuitry, suggesting that rather than abnormal recruitment of nodes in the circuit, the pathology of schizophrenia may be related to dysregulation of the underlying processing of sensory stimuli that ultimately activates these networks.

This conception of how schizophrenia symptoms arise thus integrates newer functional findings with a refined view of the structural abnormalities that may reflect the disease process itself. Structural differences in patients with schizophrenia chiefly consist of volumetric decreases, particularly of the frontal and temporal lobes, with a key, consistently demonstrated role for the hippocampus. Some functional findings provide more detailed context for the disease entity by first linking this abnormal anatomy to a proposed dysfunctional dopaminergic system originating in the midbrain. With dysregulation of midbrain tonic-phasic dopaminergic signaling that ultimately provides the basis for normal processing of stimuli, upstream cortical units involved in higher-level processing of the same stimuli are, while functioning normally in the strict neurophysiological sense, effectively processing "corrupt" information. In this way, the initial abnormal processing of the stimulus is relayed higher and higher until the clinical manifestations of schizophrenia are realized, e.g., an auditory hallucination ultimately arising from exaggerated phasic dopaminergic firing in response to a normally benign auditory stimulus. Given the previously mentioned findings of progressive loss of regional brain volume in patients with schizophrenia, it is plausible to link chronic functional abnormalities to anatomical abnormalities in an effort to explain schizophrenia symptomatology.

Of note, the dopamine hypothesis of schizophrenia is not uniformly accepted. While early Freudian theories of disordered sexual attachment have largely been discredited ${ }^{78}$ other psychodynamic theories of the etiology of psychosis have been promulgated, and remain in clinical use. ${ }^{75}$ Moreover, Montcrieff has suggested that the "dopamine hypothesis" mostly exists as a way to sell expensive neuroleptic medications. ${ }^{86}$ She suggests many neuroimaging studies are not controlled for factors that are known to increase dopamine, including arousal, stress, attention, and smoking; furthermore, she posits that postmortem studies and both urine and CSF studies of dopamine metabolites have largely been inconclusive. She has been skeptical of antipsychotic medication in general and has questioned its long-term usefulness. ${ }^{85}$ However, a recent meta-analysis of neurochemical imaging studies in schizophrenia strongly supported the dopamine hypothesis, which remains the current model with the most explanatory power. ${ }^{46}$

Recently, a model of early hippocampal hyperactivation with subsequent excitotoxicity was proposed for the pathogenesis of schizophrenia, which may explain volume loss as well as dopamine dysregulation. Schobel and colleagues note that early hyperactivation, as demonstrated by increased regional cerebral blood flow ( $\mathrm{rCBF}$ ), is predictive of progression to psychosis in high-risk individuals. ${ }^{101}$ Given the eventual hippocampal atrophy that was previously mentioned as part of the disease process of 
schizophrenia, ${ }^{66,90}$ this finding suggests that the early stages of schizophrenia are associated with hyperactivation of the hippocampus, which eventually progresses to atrophy of hippocampal tissue from constant stimulation. In a follow-up study, Schobel and colleagues proposed the neurotransmitter glutamate as a potential pathogenic driver of this process. In a mouse model of psychosis, the group demonstrated that ketamine, an $N$-methyl-D-aspartate (NMDA) receptor antagonist, forced buildup of extracellular glutamate and, in doing so, reproduced hippocampal hypermetabolism that eventually progressed to atrophic change. This change was prevented by pretreatment with an mGluR 2/3 agonist, which prevents glutamate efflux. ${ }^{100}$ This sequence of hypermetabolism followed by atrophy does not remain true for all regions with decreased gray matter in schizophrenia, however. The DLPFC, for example, does not show a similar increase in rCBF preceding atrophic change. ${ }^{20}$ The implication of the involvement of glutamate in hippocampal hyperactivation and atrophy, however, allows the pathophysiological understanding of schizophrenia to be linked not only across anatomical and functional regions of the brain, but also across neurotransmitter systems, namely the glutamatergic and dopaminergic systems.

\section{Neurochemical and PET Observations: A Key Role for the Striatum}

The "glutamate hypothesis" of schizophrenia was promulgated following observations that ketamine and phencyclidine, inhibitors of the NMDA receptor, can recapitulate the dopaminergic dysfunction observed in schizophrenia. ${ }^{2}$ Lisman and colleagues proposed an integrative framework in which deficits in GABA transmission in fast-spiking interneurons disinhibit glutamatergic pyramidal cells, which in turn stimulate dopaminergic signaling from the substantia nigra/VTA, leading to hyperdopaminergia and psychosis. ${ }^{70}$ Several lines of evidence support this hypothesis, and a number of its predictions have been verified in recent neuroimaging experiments.

Early observations that glutamatergic antagonists recapitulate schizophrenia behaviors in rodents ${ }^{50}$ were linked by evidence from elegant animal pharmacological experiments in the 1990s to the view that NMDA dysregulation drives abnormal dopamine release. ${ }^{49}$ With the availability of mice exhibiting marked downregulation of NMDA subunit NR1, it was shown that a deficiency in glutamatergic transmission produced schizophrenia-like behaviors that were ameliorated with antipsychotic medication. ${ }^{84}$ Similarly, mice lacking the dopamine transporter exhibited markedly exacerbated dopamine dysregulation with administration of NMDA antagonists, compared with controls. ${ }^{26}$

These observations motivated the performance of human experiments to confirm the glutamatergic control of dopamine signaling in patients with schizophrenia. PET studies using radiotracer-labeled ligands for the dopamine receptor confirmed both increased dopamine release to pharmacological challenge ${ }^{65}$ and baseline D2 receptor occupancy. ${ }^{1}$ Around this time, significant negative correlations of glutamate metabolites in CSF were found in patients with schizophrenia. ${ }^{114}$ Subsequently, behavioral work confirmed that administration of ketamine to patients with schizophrenia induced a transient exacerbation of psychotic symptoms. ${ }^{62}$ This experiment set the stage for others to test the glutamate hypothesis more or less directly; ketamine and amphetamine (an agent that causes both dopamine release at the synapse as well as interferes with reuptake) were coadministered to healthy controls, and a doubling of the release of dopamine in the striatum was observed. ${ }^{55}$ Similar results were obtained in nonhuman primates. ${ }^{15}$ A subsequent experiment in chronic ketamine users suggested that the DLPFC demonstrated altered dopamine activity. ${ }^{88}$ However, the anatomical substrate of the observed dopamine dysregulation was not as yet altogether clear.

Advances in neuroimaging allowed subregion analysis of cortical and subcortical structures in PET experiments. In particular, attention was focused on the AST, a region comprising the precommissural dorsal caudate, precomissural dorsal putamen, and postcommissural caudate, which exhibits extensive connectivity to the substantia nigra, DLPFC, and thalamus. ${ }^{40,51}$ Dopamine transmission was found to be elevated in the AST in both patients with schizophrenia and prodromal patients at high risk for psychosis ${ }^{47}$ Furthermore, a study imaging receptor occupancy in schizophrenia after dopamine depletion revealed alterations in transmission only within the AST, but not within the ventral or sensorimotor striatum. ${ }^{54}$ Taken together, these data are consistent with the view that dopamine dysfunction in the AST is etiologically related to the symptoms of schizophrenia.

To summarize, AST appears to be the "hotspot" of dopamine release in schizophrenia, as suggested by PET studies. Moreover, neuroanatomical and animal data suggest that it may be the locus at which glutamate dysfunction and dopamine dysfunction are linked. AST is extensively connected to the prefrontal cortex, ${ }^{22}$ and stimulation of $D_{2}$ receptors may disrupt glutamatergic transmission to local medium spiny neurons from the prefrontal cortex, ${ }^{56}$ leading to persistent behavioral abnormalities. Recent data showing normalization of glutamate levels in AST after successful antipsychotic treatment of first-episode psychosis support this view. ${ }^{17}$ Taken together, these data suggest that AST is a key locus of pathophysiology in schizophrenia.

\section{Targets for Surgical Intervention: Current Proposals and Future Directions}

As the pathophysiology of schizophrenia has become better understood, direct targeting of affected circuitry using DBS has become a possibility. In this section, we discuss several potential targets and the rationale for each.

\section{Hippocampus}

Hippocampal dysfunction has been established as a key driver of hyperdopaminergia by several lines of evidence. First, hippocampal hyperactivity has been correlated with the onset of psychosis. ${ }^{100,101}$ Moreover, in animal models, it is possible to reverse behavioral features referable to hyperdopaminergia in the striatum by targeting the hippo- 
campus using several distinct techniques: 1) tetrodotoxin inactivation, ${ }^{73}$ 2) transplant of GABA interneurons, ${ }^{27}$ and 3) DBS. ${ }^{21,92}$ However, there is no current experience in stimulating the hippocampus to treat schizophrenia.

Stimulation of the hippocampus and its related structures, including the entorhinal cortex and the fornix, has previously been used to treat epilepsy ${ }^{10,119}$ and enhance memory. ${ }^{42,67,113}$ Animal data suggest that hippocampal DBS may amplify subgranular zone neurogenesis, and these adult-born dentate neurons may integrate into circuits supporting memory. ${ }^{110}$ There is some evidence that dentate gyrus dysfunction may contribute to cognitive problems in patients with schizophrenia. ${ }^{120}$ However, the most important putative effect of hippocampal stimulation would be to modulate hyperdopaminergia in schizophrenia.

As described above, activation of the hippocampus is believed to drive dopamine release in conjunction with the substantia nigra/VTA in the setting of a novel environment or stimulus; pathological hippocampal hyperactivity in patients with schizophrenia leads to poorly timed and aberrant dopamine release. We propose that aberrant hyperactivity in the hippocampus may potentially be modulated with stimulation, leading to decreased dopamine release into the striatum. Several prior reports of hippocampal modulation in animal models of schizophrenia support this hypothesis. ${ }^{21,27,73,92}$ However, it must be mentioned that hippocampal removal has variable effects on the psychotic symptoms of patients with epilepsy and interictal psychosis. ${ }^{94}$ This observation does not invalidate our hypothesis, as it is not clear that these patients have schizophrenia, and moreover, hippocampal removal (by temporal lobectomy) is never bilateral.

There are prior reports of hippocampal stimulation in patients with epilepsy, and complications appear to be rare, with modest effects on memory. ${ }^{80,119}$ From a technical standpoint, electrode placement has mostly been described traversing the long axis of the hippocampus from an occipital approach, ${ }^{17,119}$ with the intention of stimulating the anterior part of the hippocampus, although it is also possible to place electrodes perpendicularly into the hippocampus from a temporal approach. ${ }^{116}$ Intracranial hemorrhage rates from both techniques appear to be low. ${ }^{116}$ Given this safety profile, it would be reasonable to consider a trial of hippocampal DBS for positive symptoms of refractory schizophrenia. ${ }^{81}$

\section{Ventral Striatum}

The VS is part of a polysynaptic pathway required for excessive dopamine release driven by the hippocampus. The VS receives a large glutamatergic projection from the subiculum, the output structure of the hippocampus. ${ }^{36}$ This projection is believed to perform a "gating" function on dopamine release by the VTA, ${ }^{71}$ so that the hippocampus signals through the VS to the dopaminergic midbrain to release dopamine in the setting of a novel environment or stimulus. ${ }^{71}$ Therefore, the VS is a key part of the same circuit that would be targeted with hippocampal DBS.

As above, there is surgical experience targeting the VS. Its stimulation appears to be safe and effective for the treatment of refractory $\mathrm{OCD}^{33}$ for which it has recently gained an FDA HDE. A recent SPECT study suggests that DBS of the VS modulates dopaminergic transmission at $\mathrm{D}_{2 / 3}$ receptors. We have previously proposed that the effects of DBS of the VS are consistent with stabilization of dopamine transmission. ${ }^{81}$ This mechanism could also account for its therapeutic effects in $\mathrm{MDD}^{89}$ and addiction. ${ }^{59,60}$ Moreover, error-related negativity, a marker of reward prediction error by the dopamine system, ${ }^{45}$ is decreased by VS DBS in alcoholism. ${ }^{59}$ Given these findings, VS would be a reasonable target for neuromodulation in schizophrenia; a possible mechanism of action would be modulation of dopamine transmission via local medium spiny neurons. Of note, there is 1 ongoing study in Toronto of VS DBS for schizophrenia, although no results are available yet (clinicaltrials.gov no. NCT01725334).

\section{Associative Striatum}

As previously described, the AST is a key locus of neurotransmitter dysfunction in schizophrenia. It has theoretical appeal as a target for surgical intervention for several reasons. First, it appears to be the "hotspot" of aberrant dopamine release within the striatum. ${ }^{54}$ As we have suggested previously, DBS of the axon terminals in the striatum may augment and stabilize dopaminergic transmission. ${ }^{81,105}$

Furthermore, AST exhibits extensive interconnection with parts of the brain that are implicated in the pathogenesis of schizophrenia, including the DLPFC, the orbital and medial prefrontal cortex, and the substantia nigra (Fig. 1). Finally, glutamatergic transmission within the AST appears to track symptoms after treatment with antipsychotic medications. ${ }^{17}$ The AST is therefore uniquely positioned to serve as a target to ameliorate the psychotic symptoms of schizophrenia.

It must be noted that surgical experience with stimulation of the AST is limited. However, its anatomical and physiological characteristics are well understood. By convention, the AST is defined as the precommissural dorsal caudate, precommissural dorsal putamen, and postcommissural caudate. ${ }^{76}$ This area has a large input from the DLPFC (Brodmann areas 9 and 46) (11 $^{4}$ and projects back to the dopaminergic midbrain, where it contributes to the regulation of dopamine release into the sensorimotor striatum..$^{40}$ Electrophysiologically, the striatum is characterized by phasically active units, although tonically active neurons are also observed, with functions likely distinct from phasically active, burst-type neurons. ${ }^{37}$ There are reports of DBS of the dorsal striatum for the treatment of tinnitus, suggesting that stimulation of this area may carry no more risk than what is standard to DBS in the basal ganglia. ${ }^{15,64}$

\section{Open-Loop Versus Closed-Loop Stimulation}

The availability of new DBS generators has made it possible to consider whether responsive neurostimulation could be beneficial in schizophrenia.97,112 While "openloop" stimulation is able to treat underlying neurocircuitry pathology in a continuous manner, responsive stimulation has the theoretical advantage of being able to tune neurostimulation parameters to reflect the waxing and waning nature of psychotic symptoms. Schematically, such a 


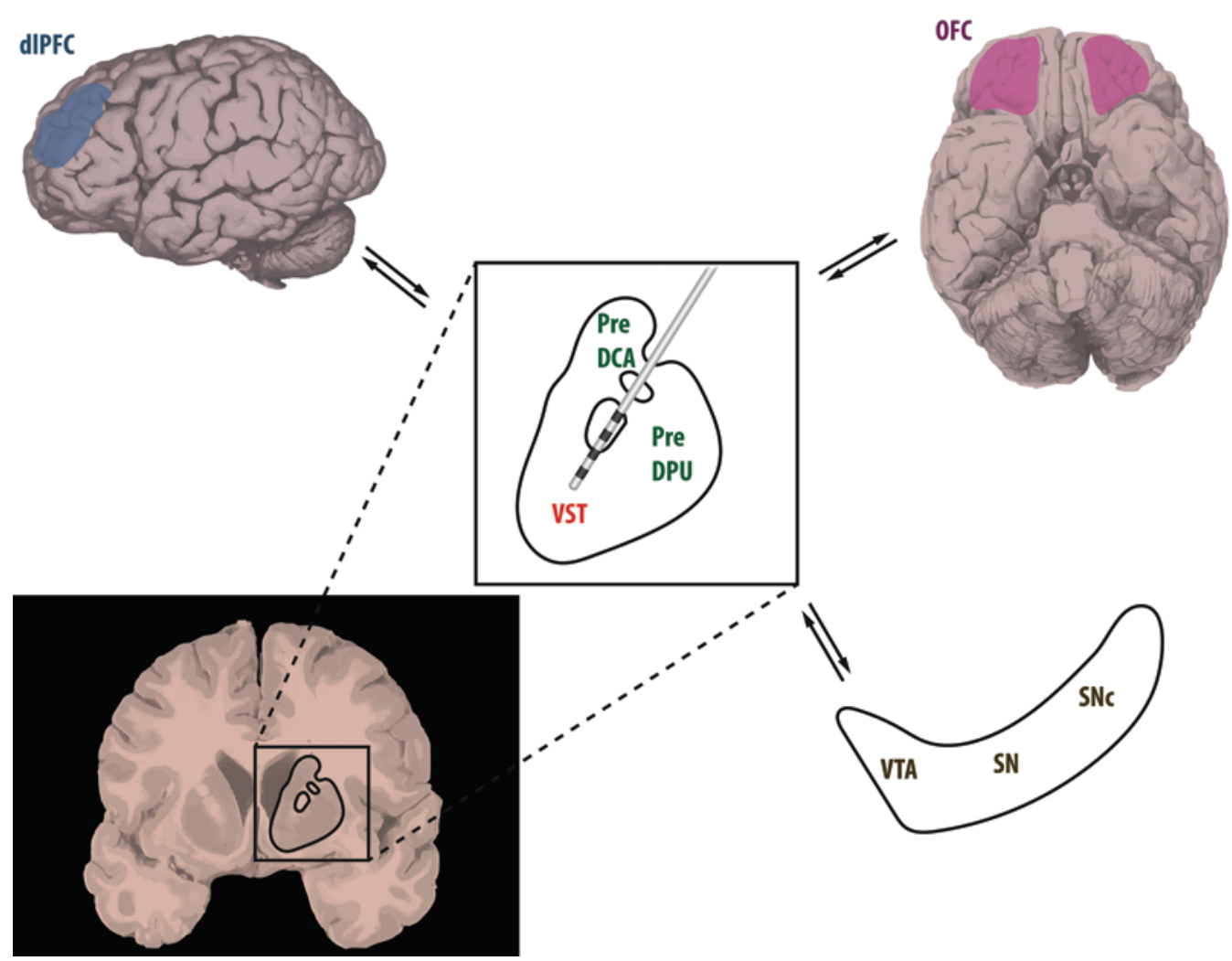

FIG. 1. The AST is a key node in the pathophysiology of schizophrenia. The AST consists of the precommissural dorsal caudate (PreDCA), precommissural dorsal putamen (PreDPU), and postcommissural caudate. Here, the inset shows the AST at the level of the PreDCA, PreDPU, and VS. The AST features extensive reciprocal connections with higher cortical areas involved in cognition, such as dorsolateral prefrontal cortex (dIPFC) and medial prefrontal cortex/orbitofrontal cortex (OFC). As shown, the AST also has important interconnections with midbrain dopaminergic regions, such as the VTA and substantia nigra (SN, shown here containing the substantia nigra pars compacta [SNc]). These midbrain regions are believed to modulate tonic-phasic dopaminergic transmission. Dysfunction of this mechanism is proposed to ultimately lead to aberrant signaling of stimulus salience in cortical control areas, manifesting as the positive symptoms of schizophrenia. The AST, serving as a connecting node between the midbrain and higher cortical areas, is thus uniquely situated as a target for DBS for schizophrenia. Figure is available in color online only.

"closed-loop" system would involve three parts: an assessment of the current state of the system (i.e., how much it has deviated from homeostasis), a control signal containing both this information and a plan for correcting it, and an effector mechanism..$^{18}$ While some neuroimaging markers do reflect the severity of delusions and/or hallucinations, the ideal control signal would have high temporal resolution and be easily detected. An electrophysiological signal (such as high gamma power in the auditory cortex, possibly reflecting hallucinations) would be ideal in this regard. We await the availability of biomarkers that track psychosis with the needed temporal resolution, because such a device could have highly specific therapeutic benefits.

\section{Testing the Hypothesis \\ Ethical Considerations}

A number of concerns arise when considering the investigation of DBS for patients with schizophrenia, chief of which are patient selection, delivery of informed consent, and clinical trial design. In fact, the ethical issues arising from the general consideration of DBS for psychi- atric disease fall into the domain of neuroethics, a subset of bioethics concerned with neuroscientific research. ${ }^{32}$ Here, we will address the major issues as listed above.

The selection of patients for the trial must first fall into a well-established definition of treatment-resistant schizophrenia. Stemming from the work of Kane and colleagues, this definition includes multiple failed trials of medication (the most essential of which is clozapine, which shows some efficacy in patients with schizophrenia who do not respond to other antipsychotics ${ }^{79}$ ), no episodes of good functioning in $\geq 5$ years, and failure to meet specific score thresholds on multiple neuropsychiatric indices. ${ }^{52}$ Beyond the appropriate designation of treatment resistance, patient selection must take into account the protection of the patient. Patients must understand the purpose and steps of the trial and be able to make consistent decisions of their own volition at all points of the trial, consistent with the basic ethical principles of autonomy and justice. ${ }^{32}$ Importantly, this is a particularly vulnerable patient population both emotionally and cognitively. Therefore, ensuring comprehension at each step is crucial, especially during the process of informed consent. 
In this patient population, informed consent can be challenging. However, existing literature suggests that it is possible to obtain. Cognitive deficits may lead to the inability to understand certain aspects of the process, but one study suggests that careful education ameliorated this deficit to a level consistent with that of healthy controls. ${ }^{12}$ The use of quizzes to ensure incremental understanding has also been suggested..$^{32}$ Moreover, the presence of a family member or loved one can help in ensuring full comprehension. Given the social isolation that accompanies schizophrenia, this may be difficult, but must be considered. In regards to the nature of the information provided in the consent, it is important to temper expectations and frankly discuss the experimental nature of the trial. Because it would be a test of efficacy, it is necessary to explain the possibility that the procedure may fail and, in fact, may even exacerbate psychosis. There is some precedent for this in VS DBS for OCD, which has been associated with hypomania. ${ }^{14,35}$ Cognitive impairment is another possible risk, given the key role of the AST in modulating information flow between the frontal lobes and thalamus. Extensive neuropsychological and psychiatric testing will be required after implantation to evaluate these possibilities.

Notably, the risks of DBS are real, but it is considered a relatively safe brain surgery. The major risks are hemorrhage $^{8}$ and infection. Hemorrhage rates have been estimated at approximately $1 \%-3 \%$ per lead implant, ${ }^{8,9,125}$ and most hemorrhages are not associated with permanent neurological deficits. ${ }^{98}$ Infection rates between $1 \%$ and $9 \%$ are reported, ${ }^{30,107}$ which do frequently require explant of the device. These considerations must be discussed with the patient prior to surgery. Finally, it must be told to the patient that explant is a possibility, regardless of infection; should the patient dislike the device for any reason, the principle of autonomy still applies, and the patient is within his or her rights to have it removed. It is reasonable to discuss this option up front in the discussion of foreseeable risks of surgery.

Important ethical considerations have to be made when designing a clinical trial of this sort. DBS is intrinsically suited to trial design, because it can be turned on or off, but this nuance presents the concurrent ethical concern of withholding treatment in control group patients. ${ }^{32}$ Accordingly, the informed consent process should take care to ensure that the details of not just the surgery, but also of the clinical trial formulation, including potential time with the stimulator on or off, are outlined.

\section{Conclusions}

DBS for most psychiatric disease remains investigational, but early studies are promising. Schizophrenia is an especially devastating disease, and major inroads have been made into understanding its pathophysiology. Converging lines of evidence suggest that dopaminergic and glutamatergic dysfunction within the striatum may lead to symptoms. Several regions in this circuitry, including the hippocampus, VS, and AST, are promising targets for neuromodulation.

\section{References}

1. Abi-Dargham A, Rodenhiser J, Printz D, Zea-Ponce Y, Gil $\mathrm{R}$, Kegeles LS, et al: Increased baseline occupancy of D2 receptors by dopamine in schizophrenia. Proc Natl Acad Sci U S A 97:8104-8109, 2000

2. Abi-Dargham A, van de Giessen E, Slifstein M, Kegeles LS, Laruelle M: Baseline and amphetamine-stimulated dopamine activity are related in drug-naïve schizophrenic subjects. Biol Psychiatry 65:1091-1093, 2009

3. Alpert M, Friedhoff AJ: An un-dopamine hypothesis of schizophrenia. Schizophr Bull 6:387-389, 1980

4. Andreasen N, Nasrallah HA, Dunn V, Olson SC, Grove WM, Ehrhardt JC, et al: Structural abnormalities in the frontal system in schizophrenia. A magnetic resonance imaging study. Arch Gen Psychiatry 43:136-144, 1986

5. Asami T, Bouix S, Whitford TJ, Shenton ME, Salisbury DF, McCarley RW: Longitudinal loss of gray matter volume in patients with first-episode schizophrenia: DARTEL automated analysis and ROI validation. Neuroimage 59:986996, 2012

6. Baiano M, David A, Versace A, Churchill R, Balestrieri M, Brambilla P: Anterior cingulate volumes in schizophrenia: a systematic review and a meta-analysis of MRI studies. Schizophr Res 93:1-12, 2007

7. Bergé D, Carmona S, Rovira M, Bulbena A, Salgado P, Vilarroya O: Gray matter volume deficits and correlation with insight and negative symptoms in first-psychotic-episode subjects. Acta Psychiatr Scand 123:431-439, 2011

8. Binder DK, Rau G, Starr PA: Hemorrhagic complications of microelectrode-guided deep brain stimulation. Stereotact Funct Neurosurg 80:28-31, 2003

9. Binder DK, Rau GM, Starr PA: Risk factors for hemorrhage during microelectrode-guided deep brain stimulator implantation for movement disorders. Neurosurgery 56:722-732, 2005

10. Boon P, Vonck K, De Herdt V, Van Dycke A, Goethals M, Goossens L, et al: Deep brain stimulation in patients with refractory temporal lobe epilepsy. Epilepsia 48:1551-1560, 2007

11. Canali P, Sferrazza Papa G, Casali AG, Schiena G, Fecchio M, Pigorini A, et al: Changes of cortical excitability as markers of antidepressant response in bipolar depression: preliminary data obtained by combining transcranial magnetic stimulation (TMS) and electroencephalography (EEG). Bipolar Disord 16:809-819, 2014

12. Carpenter WT Jr, Gold JM, Lahti AC, Queern CA, Conley RR, Bartko JJ, et al: Decisional capacity for informed consent in schizophrenia research. Arch Gen Psychiatry 57:533-538, 2000

13. Carter CS, Robertson LC, Nordahl TE: Abnormal processing of irrelevant information in chronic schizophrenia: selective enhancement of Stroop facilitation. Psychiatry Res 41: 137-146, 1992

14. Chang CH, Chen SY, Hsiao YL, Tsai ST, Tsai HC: Hypomania with hypersexuality following bilateral anterior limb stimulation in obsessive-compulsive disorder. J Neurosurg 112:1299-1300, 2010

15. Cheung SW, Larson PS: Tinnitus modulation by deep brain stimulation in locus of caudate neurons (area LC). Neuroscience 169:1768-1778, 2010

16. Daskalakis ZJ: Deep brain stimulation (DBS) for the management of treatment refractory negative symptoms in schizophrenia. ClinicalTrials.gov. (http://clinicaltrials.gov/ ct2/show/NCT01725334) [Accessed August 6, 2015]

17. de la Fuente-Sandoval C, León-Ortiz P, Azcárraga M, Stephano S, Favila R, Díaz-Galvis L, et al: Glutamate levels in the associative striatum before and after 4 weeks of antipsychotic treatment in first-episode psychosis: a longitudi- 
nal proton magnetic resonance spectroscopy study. JAMA Psychiatry 70:1057-1066, 2013

18. Doyle JC, Francis BA, Tannenbaum AR: Feedback Control Theory. Mineola, NY: Dover Publications, 2009

19. Eberle MC, Wildgruber D, Wasserka B, Fallgatter AJ, Plewnia C: Relief from chronic intractable auditory hallucinations after long-term bilateral theta burst stimulation. Am J Psychiatry 167:1410, 2010

20. Eggers AE: An explanation of why schizophrenia begins with excitotoxic damage to the hippocampus. Med Hypotheses 81:1056-1058, 2013

21. Ewing SG, Grace AA: Deep brain stimulation of the ventral hippocampus restores deficits in processing of auditory evoked potentials in a rodent developmental disruption model of schizophrenia. Schizophr Res 143:377-383, 2013

22. Ferry AT, Ongür D, An X, Price JL: Prefrontal cortical projections to the striatum in macaque monkeys: evidence for an organization related to prefrontal networks. J Comp Neurol 425:447-470, 2000

23. Flashman LA, McAllister TW, Johnson SC, Rick JH, Green RL, Saykin AJ: Specific frontal lobe subregions correlated with unawareness of illness in schizophrenia: a preliminary study. J Neuropsychiatry Clin Neurosci 13:255-257, 2001

24. Floresco SB, Todd CL, Grace AA: Glutamatergic afferents from the hippocampus to the nucleus accumbens regulate activity of ventral tegmental area dopamine neurons. J Neurosci 21:4915-4922, 2001

25. Frantseva M, Cui J, Farzan F, Chinta LV, Perez Velazquez JL, Daskalakis ZJ: Disrupted cortical conductivity in schizophrenia: TMS-EEG study. Cereb Cortex 24:211-221, 2014

26. Gainetdinov RR, Mohn AR, Bohn LM, Caron MG: Glutamatergic modulation of hyperactivity in mice lacking the dopamine transporter. Proc Natl Acad Sci U S A 98:11047-11054, 2001

27. Gilani AI, Chohan MO, Inan M, Schobel SA, Chaudhury $\mathrm{NH}$, Paskewitz $\mathrm{S}$, et al: Interneuron precursor transplants in adult hippocampus reverse psychosis-relevant features in a mouse model of hippocampal disinhibition. Proc Natl Acad Sci U S A 111:7450-7455, 2014

28. Goldman-Rakic PS, Castner SA, Svensson TH, Siever LJ, Williams GV: Targeting the dopamine D1 receptor in schizophrenia: insights for cognitive dysfunction. Psychopharmacology (Berl) 174:3-16, 2004

29. Goodman WK, Foote KD, Greenberg BD, Ricciuti N, Bauer $\mathrm{R}$, Ward H, et al: Deep brain stimulation for intractable obsessive compulsive disorder: pilot study using a blinded, staggered-onset design. Biol Psychiatry 67:535-542, 2010

30. Gorgulho A, Juillard C, Uslan DZ, Tajik K, Aurasteh P, Behnke E, et al: Infection following deep brain stimulator implantation performed in the conventional versus magnetic resonance imaging-equipped operating room. J Neurosurg 110:239-246, 2009

31. Goto Y, Grace AA: The dopamine system and the pathophysiology of schizophrenia: a basic science perspective. Int Rev Neurobiol 78:41-68, 2007

32. Grant RA, Halpern CH, Baltuch GH, O'Reardon JP, Caplan A: Ethical considerations in deep brain stimulation for psychiatric illness. J Clin Neurosci 21: 1-5, 2014

33. Greenberg BD, Gabriels LA, Malone DA Jr, Rezai AR, Friehs GM, Okun MS, et al: Deep brain stimulation of the ventral internal capsule/ventral striatum for obsessive-compulsive disorder: worldwide experience. Mol Psychiatry 15:64-79, 2010

34. Greenberg BD, Malone DA, Friehs GM, Rezai AR, Kubu CS, Malloy PF, et al: Three-year outcomes in deep brain stimulation for highly resistant obsessive-compulsive disorder. Neuropsychopharmacology 31:2384-2393, 2006

35. Greenberg BD, Ziemann U, Corá-Locatelli G, Harmon A, Murphy DL, Keel JC, et al: Altered cortical excitability in obsessive-compulsive disorder. Neurology 54:142-147, 2000

36. Groenewegen HJ, Vermeulen-Van der Zee E, te Kortschot A, Witter MP: Organization of the projections from the subiculum to the ventral striatum in the rat. A study using anterograde transport of Phaseolus vulgaris leucoagglutinin. Neuroscience 23:103-120, 1987

37. Gross RE, Krack P, Rodriguez-Oroz MC, Rezai AR, Benabid AL: Electrophysiological mapping for the implantation of deep brain stimulators for Parkinson's disease and tremor. Mov Disord 21 (Suppl 14):S259-S283, 2006

38. Gur RE, Turetsky BI, Cowell PE, Finkelman C, Maany V, Grossman RI, et al: Temporolimbic volume reductions in schizophrenia. Arch Gen Psychiatry 57:769-775, 2000

39. Gureje O, Herrman H, Harvey C, Morgan V, Jablensky A: The Australian National Survey of Psychotic Disorders: profile of psychosocial disability and its risk factors. Psychol Med 32:639-647, 2002

40. Haber SN, Fudge JL, McFarland NR: Striatonigrostriatal pathways in primates form an ascending spiral from the shell to the dorsolateral striatum. J Neurosci 20:2369-2382, 2000

41. Haber SN, Kim KS, Mailly P, Calzavara R: Reward-related cortical inputs define a large striatal region in primates that interface with associative cortical connections, providing a substrate for incentive-based learning. J Neurosci 26:83688376, 2006

42. Hamani C, McAndrews MP, Cohn M, Oh M, Zumsteg D, Shapiro CM, et al: Memory enhancement induced by hypothalamic/fornix deep brain stimulation. Ann Neurol 63:119-123, 2008

43. Hill K, Mann L, Laws KR, Stephenson CME, NimmoSmith I, McKenna PJ: Hypofrontality in schizophrenia: a meta-analysis of functional imaging studies. Acta Psychiatr Scand 110:243-256, 2004

44. Hirayasu Y, Tanaka S, Shenton ME, Salisbury DF, DeSantis MA, Levitt JJ, et al: Prefrontal gray matter volume reduction in first episode schizophrenia. Cereb Cortex 11:374-381, 2001

45. Holroyd CB, Coles MGH: The neural basis of human error processing: reinforcement learning, dopamine, and the error-related negativity. Psychol Rev 109:679-709, 2002

46. Howes OD, Kambeitz J, Kim E, Stahl D, Slifstein M, AbiDargham A, et al: The nature of dopamine dysfunction in schizophrenia and what this means for treatment. Arch Gen Psychiatry 69:776-786, 2012

47. Howes OD, Montgomery AJ, Asselin M-C, Murray RM, Valli I, Tabraham P, et al: Elevated striatal dopamine function linked to prodromal signs of schizophrenia. Arch Gen Psychiatry 66:13-20, 2009

48. Howes OD, Murray RM: Schizophrenia: an integrated sociodevelopmental-cognitive model. Lancet 383:16771687,2014

49. Imperato A, Scrocco MG, Bacchi S, Angelucci L: NMDA receptors and in vivo dopamine release in the nucleus accumbens and caudatus. Eur J Pharmacol 187:555-556, 1990

50. Javitt DC, Zukin SR: Recent advances in the phencyclidine model of schizophrenia. Am J Psychiatry 148:1301-1308, 1991

51. Joel D, Weiner I: The connections of the dopaminergic system with the striatum in rats and primates: an analysis with respect to the functional and compartmental organization of the striatum. Neuroscience 96:451-474, 2000

52. Kane J, Honigfeld G, Singer J, Meltzer H: Clozapine for the treatment-resistant schizophrenic. A double-blind comparison with chlorpromazine. Arch Gen Psychiatry 45:789796, 1988

53. Kapur S: Psychosis as a state of aberrant salience: a frame- 
work linking biology, phenomenology, and pharmacology in schizophrenia. Am J Psychiatry 160: 13-23, 2003

54. Kegeles LS, Abi-Dargham A, Frankle WG, Gil R, Cooper TB, Slifstein M, et al: Increased synaptic dopamine function in associative regions of the striatum in schizophrenia. Arch Gen Psychiatry 67:231-239, 2010

55. Kegeles LS, Abi-Dargham A, Zea-Ponce Y, RodenhiserHill J, Mann JJ, Van Heertum RL, et al: Modulation of amphetamine-induced striatal dopamine release by ketamine in humans: implications for schizophrenia. Biol Psychiatry 48:627-640, 2000

56. Kellendonk C, Simpson EH, Polan HJ, Malleret G, Vronskaya S, Winiger V, et al: Transient and selective overexpression of dopamine D2 receptors in the striatum causes persistent abnormalities in prefrontal cortex functioning. Neuron 49:603-615, 2006

57. Kerwin RW, Bolonna A: Management of clozapine-resistant schizophrenia. Adv Psychiatr Treat 11:101-106, 2005

58. Kindler J, Homan P, Flury R, Strik W, Dierks T, Hubl D: Theta burst transcranial magnetic stimulation for the treatment of auditory verbal hallucinations: results of a randomized controlled study. Psychiatry Res 209:114-117, 2013

59. Kuhn J, Gründler TOJ, Bauer R, Huff W, Fischer AG, Lenartz D, et al: Successful deep brain stimulation of the nucleus accumbens in severe alcohol dependence is associated with changed performance monitoring. Addict Biol 16:620-623, 2011

60. Kuhn J, Lenartz D, Huff W, Lee S, Koulousakis A, Klosterkoetter J, et al: Remission of alcohol dependency following deep brain stimulation of the nucleus accumbens: valuable therapeutic implications? J Neurol Neurosurg Psychiatry 78:1152-1153, 2007

61. Kühn S, Musso F, Mobascher A, Warbrick T, Winterer G, Gallinat J: Hippocampal subfields predict positive symptoms in schizophrenia: first evidence from brain morphometry. Transl Psychiatry 2:e127, 2012

62. Lahti AC, Koffel B, LaPorte D, Tamminga CA: Subanesthetic doses of ketamine stimulate psychosis in schizophrenia. Neuropsychopharmacology 13:9-19, 1995

63. Larøi F, Fannemel M, Rønneberg U, Flekkøy K, Opjordsmoen S, Dullerud R, et al: Unawareness of illness in chronic schizophrenia and its relationship to structural brain measures and neuropsychological tests. Psychiatry Res 100:49-58, 2000

64. Larson PS, Cheung SW: A stroke of silence: tinnitus suppression following placement of a deep brain stimulation electrode with infarction in area LC. J Neurosurg 118:192194, 2013

65. Laruelle M, Abi-Dargham A, van Dyck CH, Gil R, D’Souza $\mathrm{CD}$, Erdos J, et al: Single photon emission computerized tomography imaging of amphetamine-induced dopamine release in drug-free schizophrenic subjects. Proc Natl Acad Sci U S A 93:9235-9240, 1996

66. Lawrie SM, Abukmeil SS: Brain abnormality in schizophrenia. A systematic and quantitative review of volumetric magnetic resonance imaging studies. Br J Psychiatry 172: 110-120, 1998

67. Laxton AW, Tang-Wai DF, McAndrews MP, Zumsteg D, Wennberg R, Keren R, et al: A phase I trial of deep brain stimulation of memory circuits in Alzheimer's disease. Ann Neurol 68:521-534, 2010

68.Lehman AF, Lieberman JA, Dixon LB, McGlashan TH, Miller AL, Perkins DO, et al: Practice guideline for the treatment of patients with schizophrenia, second edition. Am J Psychiatry 161 (2 Suppl): 1-56, 2004

69. Lipsman N, Giacobbe P, Lozano AM: Deep brain stimulation in obsessive-compulsive disorder: neurocircuitry and clinical experience. Handb Clin Neurol 116:245-250, 2013
70. Lisman JE, Coyle JT, Green RW, Javitt DC, Benes FM, Heckers S, et al: Circuit-based framework for understanding neurotransmitter and risk gene interactions in schizophrenia. Trends Neurosci 31:234-242, 2008

71. Lisman JE, Grace AA: The hippocampal-VTA loop: controlling the entry of information into long-term memory. Neuron 46: 703-713, 2005

72. Liu SK, Fitzgerald PB, Daigle M, Chen R, Daskalakis $\mathrm{ZJ}$ : The relationship between cortical inhibition, antipsychotic treatment, and the symptoms of schizophrenia. Biol Psychiatry 65:503-509, 2009

73. Lodge DJ, Grace AA: Aberrant hippocampal activity underlies the dopamine dysregulation in an animal model of schizophrenia. J Neurosci 27:11424-11430, 2007

74. Lyon GJ, Abi-Dargham A, Moore H, Lieberman JA, Javitch JA, Sulzer D: Presynaptic regulation of dopamine transmission in schizophrenia. Schizophr Bull 37:108-117, 2011

75. Martindale B, Summers A: The psychodynamics of psychosis. Adv Psychiatr Treat 19:124-131, 2013

76. Martinez D, Slifstein M, Broft A, Mawlawi O, Hwang DR, Huang Y, et al: Imaging human mesolimbic dopamine transmission with positron emission tomography. Part II: amphetamine-induced dopamine release in the functional subdivisions of the striatum. J Cereb Blood Flow Metab 23:285-300, 2003

77. McClintock SM, Freitas C, Oberman L, Lisanby SH, Pascual-Leone A: Transcranial magnetic stimulation: a neuroscientific probe of cortical function in schizophrenia. Biol Psychiatry 70:19-27, 2011

78. McGlashan TH: Psychosis as a disorder of reduced cathectic capacity: Freud's analysis of the Schreber case revisited. Schizophr Bull 35:476-481, 2009

79. McIlwain ME, Harrison J, Wheeler AJ, Russell BR: Pharmacotherapy for treatment-resistant schizophrenia. Neuropsychiatr Dis Treat 7:135-149, 2011

80. McLachlan RS, Pigott S, Tellez-Zenteno JF, Wiebe S, Parrent A: Bilateral hippocampal stimulation for intractable temporal lobe epilepsy: impact on seizures and memory. Epilepsia 51:304-307, 2010

81. Mikell CB, McKhann GM, Segal S, McGovern RA, Wallenstein MB, Moore H: The hippocampus and nucleus accumbens as potential therapeutic targets for neurosurgical intervention in schizophrenia. Stereotact Funct Neurosurg 87:256-265, 2009

82. Mikell CB, Sheehy JP, Youngerman BE, McGovern RA, Wojtasiewicz TJ, Chan AK, et al: Features and timing of the response of single neurons to novelty in the substantia nigra. Brain Res 1542:79-84, 2014

83. Minzenberg MJ, Laird AR, Thelen S, Carter CS, Glahn DC: Meta-analysis of 41 functional neuroimaging studies of executive function in schizophrenia. Arch Gen Psychiatry 66:811-822, 2009

84. Mohn AR, Gainetdinov RR, Caron MG, Koller BH: Mice with reduced NMDA receptor expression display behaviors related to schizophrenia. Cell 98:427-436, 1999

85. Moncrieff J: The Bitterest Pills: The Troubling Story of Antipsychotic Drugs. New York: Palgrave Macmillan, 2013

86. Moncrieff $\mathrm{J}$ : A critique of the dopamine hypothesis of schizophrenia and psychosis. Harv Rev Psychiatry 17:214-225, 2009

87. Murray GK, Corlett PR, Clark L, Pessiglione M, Blackwell $\mathrm{AD}$, Honey G, et al: Substantia nigra/ventral tegmental reward prediction error disruption in psychosis. Mol Psychiatry 13:239, 267-276, 2008

88. Narendran R, Frankle WG, Keefe R, Gil R, Martinez D, Slifstein M, et al: Altered prefrontal dopaminergic function in chronic recreational ketamine users. Am J Psychiatry 162:2352-2359, 2005 
89. Nauczyciel C, Robic S, Dondaine T, Verin M, Robert G, Drapier D, et al: The nucleus accumbens: a target for deep brain stimulation in resistant major depressive disorder. J Mol Psychiatry 1:17, 2013

90. Nelson MD, Saykin AJ, Flashman LA, Riordan HJ: Hippocampal volume reduction in schizophrenia as assessed by magnetic resonance imaging: a meta-analytic study. Arch Gen Psychiatry 55:433-440, 1998

91. Ooms P, Mantione M, Figee M, Schuurman PR, van den Munckhof P, Denys D: Deep brain stimulation for obsessive-compulsive disorders: long-term analysis of quality of life. J Neurol Neurosurg Psychiatry 85:153-158, 2014

92. Perez SM, Shah A, Asher A, Lodge DJ: Hippocampal deep brain stimulation reverses physiological and behavioural deficits in a rodent model of schizophrenia. Int J Neuropsychopharmacol 16:1331-1339, 2013

93. Regier DA, Narrow WE, Rae DS, Manderscheid RW, Locke BZ, Goodwin FK: The de facto US mental and addictive disorders service system. Epidemiologic catchment area prospective 1-year prevalence rates of disorders and services. Arch Gen Psychiatry 50:85-94, 1993

94. Reutens DC, Savard G, Andermann F, Dubeau F, Olivier A: Results of surgical treatment in temporal lobe epilepsy with chronic psychosis. Brain 120:1929-1936, 1997

95. Roiser JP, Howes OD, Chaddock CA, Joyce EM, McGuire P: Neural and behavioral correlates of aberrant salience in individuals at risk for psychosis. Schizophr Bull 39:13281336,2013

96. Rothwell JC, Day BL, Thompson PD, Kujirai T: Short latency intracortical inhibition: one of the most popular tools in human motor neurophysiology. J Physiol 587:1112,2009

97. Ryapolova-Webb E, Afshar P, Stanslaski S, Denison T, de Hemptinne C, Bankiewicz K, et al: Chronic cortical and electromyographic recordings from a fully implantable device: preclinical experience in a nonhuman primate. $\mathbf{J}$ Neural Eng 11:016009, 2014

98. Sansur CA, Frysinger RC, Pouratian N, Fu K-M, Bittl M, Oskouian RJ, et al: Incidence of symptomatic hemorrhage after stereotactic electrode placement. J Neurosurg 107:998-1003, 2007

99. Schapiro MB, Berman KF, Alexander GE, Weinberger DR, Rapoport SI: Regional cerebral blood flow in Down syndrome adults during the Wisconsin Card Sorting Test: exploring cognitive activation in the context of poor performance. Biol Psychiatry 45:1190-1196, 1999

100. Schobel SA, Chaudhury NH, Khan UA, Paniagua B, Styner MA, Asllani I, et al: Imaging patients with psychosis and a mouse model establishes a spreading pattern of hippocampal dysfunction and implicates glutamate as a driver. Neuron 78:81-93, 2013

101. Schobel SA, Lewandowski NM, Corcoran CM, Moore H, Brown T, Malaspina D, et al: Differential targeting of the CA1 subfield of the hippocampal formation by schizophrenia and related psychotic disorders. Arch Gen Psychiatry 66:938-946, 2009

102. Schultz W: Updating dopamine reward signals. Curr Opin Neurobiol 23:229-238, 2013

103. Seeman P, Lee T: Antipsychotic drugs: direct correlation between clinical potency and presynaptic action on dopamine neurons. Science 188:1217-1219, 1975

104. Shenton ME, Dickey CC, Frumin M, McCarley RW: A review of MRI findings in schizophrenia. Schizophr Res 49:1-52, 2001

105. Shon YM, Lee KH, Goerss SJ, Kim IY, Kimble C, Van Gompel JJ, et al: High frequency stimulation of the subthalamic nucleus evokes striatal dopamine release in a large animal model of human DBS neurosurgery. Neurosci Lett 475:136-140, 2010
106. Sidhoumi D, Braha S, Bouaziz N, Brunelin J, Benadhira R, Januel D: Evaluation of the therapeutic effect of theta burst stimulation on drug-resistant auditory hallucinations in a schizophrenic patient and its impact on cognitive function and neuronal excitability: a case study. Clin Neurophysiol 121:802, 2010

107. Sillay KA, Larson PS, Starr PA: Deep brain stimulator hardware-related infections: incidence and management in a large series. Neurosurgery 62:360-367, 2008

108. Simon W, Wirt RD, Wirt AL, Halloran AV, Hinckley RG, Lund JB, et al: A controlled study of the short-term differential treatment of schizophrenia. Am J Psychiatry 114:1077-1086, 1958

109. Snyder SH: The dopamine hypothesis of schizophrenia: focus on the dopamine receptor. Am J Psychiatry 133:197-202, 1976

110. Stone SSD, Teixeira CM, Devito LM, Zaslavsky K, Josselyn SA, Lozano AM, et al: Stimulation of entorhinal cortex promotes adult neurogenesis and facilitates spatial memory. J Neurosci 31:13469-13484, 2011

111. Sturm V, Fricke O, Bührle CP, Lenartz D, Maarouf M, Treuer H, et al: DBS in the basolateral amygdala improves symptoms of autism and related self-injurious behavior: a case report and hypothesis on the pathogenesis of the disorder. Front Hum Neurosci 6:341, 2012

112. Sun FT, Morrell MJ: Closed-loop neurostimulation: the clinical experience. Neurotherapeutics 11:553-563, 2014

113. Suthana N, Haneef Z, Stern J, Mukamel R, Behnke E, Knowlton B, et al: Memory enhancement and deep-brain stimulation of the entorhinal area. N Engl J Med 366:502510,2012

114. Tsai G, van Kammen DP, Chen S, Kelley ME, Grier A, Coyle JT: Glutamatergic neurotransmission involves structural and clinical deficits of schizophrenia. Biol Psychiatry 44:667-674, 1998

115. van Berckel BNM, Kegeles LS, Waterhouse R, Guo N, Hwang D-R, Huang Y, et al: Modulation of amphetamineinduced dopamine release by group II metabotropic glutamate receptor agonist LY354740 in non-human primates studied with positron emission tomography. Neuropsychopharmacology 31:967-977, 2006

116. Van Gompel JJ, Meyer FB, Marsh WR, Lee KH, Worrell GA: Stereotactic electroencephalography with temporal grid and mesial temporal depth electrode coverage: does technique of depth electrode placement affect outcome? J Neurosurg 113:32-38, 2010

117. Velasco AL, Velasco F, Velasco M, Jiménez F, CarrilloRuiz JD, Castro G: The role of neuromodulation of the hippocampus in the treatment of intractable complex partial seizures of the temporal lobe. Acta Neurochir Suppl 97:329-332, 2007

118. Vita A, De Peri L, Deste G, Sacchetti E: Progressive loss of cortical gray matter in schizophrenia: a meta-analysis and meta-regression of longitudinal MRI studies. Transl Psychiatry 2:e190, 2012

119. Vonck K, Boon P, Achten E, De Reuck J, Caemaert J: Long-term amygdalohippocampal stimulation for refractory temporal lobe epilepsy. Ann Neurol 52:556-565, 2002

120. Walton NM, Zhou Y, Kogan JH, Shin R, Webster M, Gross AK, et al: Detection of an immature dentate gyrus feature in human schizophrenia/bipolar patients. Transl Psychiatry 2:e135, 2012

121. White TP, Gilleen J, Shergill SS: Dysregulated but not decreased salience network activity in schizophrenia. Front Hum Neurosci 7:65, 2013

122. Winton-Brown TT, Fusar-Poli P, Ungless MA, Howes OD: Dopaminergic basis of salience dysregulation in psychosis. Trends Neurosci 37:85-94, 2014

123. Wittmann BC, Schott BH, Guderian S, Frey JU, Heinze HJ, 
Düzel E: Reward-related FMRI activation of dopaminergic midbrain is associated with enhanced hippocampus-dependent long-term memory formation. Neuron 45:459-467, 2005

124. Zhao S, Kong J, Li S, Tong Z, Yang C, Zhong H: Randomized controlled trial of four protocols of repetitive transcranial magnetic stimulation for treating the negative symptoms of schizophrenia. Shanghai Arch Psychiatry 26: $15-21,2014$

125. Zrinzo L, Foltynie T, Limousin P, Hariz MI: Reducing hemorrhagic complications in functional neurosurgery: a large case series and systematic literature review. J Neurosurg 116:84-94, 2012

\section{Disclosure}

The authors report no conflict of interest concerning the materi- als or methods used in this study or the findings specified in this paper.

\section{Author Contributions}

Conception and design: all authors. Acquisition of data: Mikell, Sinha. Analysis and interpretation of data: Mikell, Sinha. Drafting the article: Mikell, Sinha. Critically revising the article: Sheth, Mikell. Reviewed submitted version of manuscript: all authors. Study supervision: Sheth.

\section{Correspondence}

Sameer A. Sheth, Department of Neurological Surgery, Columbia University Medical Center, 710 W. 168th St., New York, NY 10032.email: ss4451@cumc.columbia.edu. 